\title{
Comparative Analysis of a Novel Material, GPRA as Partial Replacement in Coarse Aggregate with Individual Materials
}

\author{
Obair Bilal Shah $^{1}$, Ashish Kumar ${ }^{2}$, and Dr. Sandeep Kumar Chandel ${ }^{3}$ \\ 1,2 Department of Civil Engineering, RIMT University, Mandi, Gobindgarh, Punjab, India \\ ${ }^{3}$ Assistant Professor, Department of Civil Engineering, RIMT University, Mandi, Gobindgarh, Punjab, India \\ Correspondence should be addressed to Bilal Shah; rimt.ce10952@gmail.com
}

Copyright (C) 2022 Obair Bilal Shah et al. This is an open access article distributed under the Creative Commons Attribution License, which permits unrestricted use, distribution, and reproduction in any medium, provided the original work is properly cited

\begin{abstract}
GPRA is a unique material made up of shredded glass, plastic, rubber, and aluminum particles. Concrete is abundantly used building material on the planet, requiring around 12.6 billion tons of natural resources to produce. All of the elements in concrete are partially or completely replaced by a variety of waste products, such as fly ash, rice husk ash, wheat straw ash, and so on. Rapid urbanization and industrialization around the world has resulted in large amounts of plastic trash and waste tyre rubber being deposited. This trash can be used to lower the coarse aggregate content of concrete when used in the proper conditions. This research work looks at the potential of a novel compound GPRA i.e. (Glass, Plastic, Rubber, Aluminum) as a partial replacement in coarse aggregate. Though there has been enough research on use of waste materials as replacement in concrete structures with an aim to curb pollution levels. This research work aims to utilize properties of waste materials which may give a higher performance than individually using of waste materials and while lowering of various pollution levels with cost effective ways for partial replacement of coarse aggregates in concrete, shredded waste materials for GPRA with sizes ranging from 4.75 to $20 \mathrm{~mm}$ will be employed. This investigation will use an M30 design mix with a target mean strength of $42 \mathrm{n} / \mathrm{mm} 2$. GPRA will be used to partially replace coarse aggregate in the following percentages: $10 \%, 30 \%$, and $40 \%$. The C.S., S.T.S., and F.S. of GPRA in hardened concrete has to be compared to the individual replacement of these waste materials.
\end{abstract}

KEYWORDS- GPRA, Concrete, Waste Materials, Aggregate Concrete Mixtures

\section{INTRODUCTION}

The country's increasing demands has resulted in significant infrastructural development. This process causes a number of

concerns, including a shortage of construction supplies and increasing waste and other non-biodegradable components. Wastes of many forms are produced as human race of infrastructure goes on. Waste disposal has become a concern as a result of the emergence of non-decaying and low biodegradable waste products, as well as an increasing consumer population. With increased development comes an increase in construction costs and pollution. Engineers and designers have been on the lookout for new ways to incorporate waste materials into cement concrete blocks. Concrete is a composite material that is made up of C.A. and cement. The coarse aggregates used in concrete production are either naturally occurring or crushed rock, which is not readily available in all construction areas, raising the cost. Partially replacing C.A. is an alternative to this problem. Although glass makes up around 5-10\% of municipal solid waste, only a small portion of it is recycled. It is estimated that several million tonnes of waste glass is generated annually around the world as a result of population increase, rising living standards, industry, and urbanisation. Year by year, the use of rubber products grows in popularity around the world. In many Indian cities, discarded tyres constitute a big environmental issue. In India, more than 1 billion trash tyres are produced each year, or around one tyre per person. Approximately $80 \%$ of scrap tyres are disposed in landfills. It is not only inefficient, but also costly, to bury scrap tyres in landfills. Landfilling of entire or shredded tyres is prohibited under recent EU laws on waste disposal (Council Directive 1999/31/EC). From 1950 to 2018, an estimated 6.3 billion tonnes of plastic were produced worldwide, with 9 percent recycled and the remaining 12 percent burnt. In India, more than 5 MT of plastic are used each year, with only about a one fourth being recycled and the rest ending up in 
landfills. This massive volume of plastic garbage inevitably finds its way into the environment, with studies estimating that 90 percent of seabirds' bodies include plastic debris. For a long time, aluminium goods such as aluminium caps were seen as waste. They've been employed in the construction sector to partially replace fine and coarse materials with great success.

\section{OBJECTIVES}

An attempt has been made in the present work to develop a GPRA concrete and to assess its strength and durability characteristics.

The following are the objectives carried in the present work.

- To assess the properties GPRA concrete by mix design for M30 grade of concrete

- To study the strength characteristics of GPRA concrete of M30 grade of concrete with different percentages of GPRA $(10 \%, 20 \%, 30 \%, 40 \%)$

- To carry out various preliminary tests like Vee-Bee time test, slump test, compaction factor tests etc.

- To study the durability performance of GPRA concrete

- To evaluate the performance characteristics of GPRA by plotting graphs and comparing the test results of C.S., flexural and S.T.S. of GPRA with individual materials.

\section{DEFINITION OF GPRA}

It is important at this stage to define GPRA and its characteristics. Literally, GPRA is compound which involves a defined and shredded mixture of Glass, plastic, rubber and aluminium. The GPRA is used as partial replacement of C.A. in concrete composition. concrete cement are often partially replaced by different supplementary bonding materials. In the recent years rubber, glass powder and silica fume are used in concrete as a partial cement replacement to improve the strength of concrete. So, the mixture of these materials considering their properties, we stated a new compound as GPRA.

\section{LITRERATURE REVIEW}

\section{A. Sakale et al 2016 [1]}

The effects of replacing fine aggregate with waste glass powder by volume of cement in steps of $10-40 \%$ were investigated, and the impacts on C.S., S.T.S., workability, and F.S. were closely studied. The compressive, flexural, and S.T.S. of concrete are shown to increase initially as glass powder increases, peaking at around $20 \%$, and thereafter declining. Concrete's workability decreases in a linear fashion as the replacement \% rises. Glass powder can be used to replace cement up to $20 \%$ without affecting C.S.

\section{B. Dr. K. C. Reddy et al 2017 [2]}

It is recommended that a combination of aluminium powder and fly ash be used to replace 5\%,10\%, and $15 \%$ of the cement in the mixture. There it showed a steady drop in C.S. and S.T.S. with the addition of aluminium powder. Higher compressive and S.T.S. are achieved when fly ash $(15 \%)$ and aluminium powder $(0.25 \%)$ are used.

\section{Subramani et al 2015 [3]}

The use of plastic trash as a substitute for conventional C.A. improves the physical and mechanical qualities of concrete mixtures, according to the study. The tests of concrete were reported to have increased by $8 \%, 5 \%$, and $3 \%$, respectively, when compared to control concrete at a $15 \%$ replacement level. As the percentage of concrete replacement surpassed $15 \%$, all of the qualities of concrete began to deteriorate. This was due to an excessive amount of water in the concrete mix, as plastic garbage has a far lower water absorption rate than traditional C.A.

\section{Sara et al 2010 [4]}

The study investigates the influence of rubber particles on some concrete qualities. The results suggest that incorporating rubber aggregates produced from waste tyres into concrete is a viable method for reducing weight in various engineering products. She also mentioned several disadvantages, such as a significant reduction in C.S. and an increase in water demand and air content. However, the test results revealed that rubberized concrete mix has fascinating qualities that can be used in structural and nonstructural applications. The test results also reveal that the type and content of rubber particles, as well as cement type and additive qualities, have a substantial impact on concrete performance.

\section{E. Harini et al 2015 [5]}

The impact of using plastic trash as fine aggregate and silica fume as cement in concrete mixes was investigated. Plastic waste was replaced in concrete in various percentages by weight. They stated that all of the replacement levels had a high degree of workability. It was also claimed that all replacement levels of plastic waste as fine aggregate resulted in a minor drop in C.S. of $\mathrm{r} 10 \%$ when compared to control mix. The C.S. of concrete mixes rose up by $13 \%, 20 \%$, and $23 \%$ when silica fume was replaced with $5 \%, 10 \%$, and $15 \%$, respectively. In comparison to the control mix, tensile strength of concrete decreased moderately by $8 \%$ to $20 \%$ replacement levels and increased significantly at $5 \%$ and $6 \%$ replacement levels.

\section{MATERIALS AND METHODOLOGY}

\section{A. Materials}

1) Cement

In this study, ordinary Portland cement (OPC) of grade 53 from a local market was employed. The cement used was tested for various proportions in accordance with IS 40311988 and determined to meet various standards in accordance with IS 12269-1987. The fineness was 2700 $\mathrm{cm} 2 / \mathrm{gm}$ and the specific gravity was 3.03 . 


\section{2) Coarse Aggregate}

In this investigation, crushed angular granite metal of C.A. with a maximum size of $20 \mathrm{~mm}$ and a minimum size of 12 $\mathrm{mm}$ was obtained from a local crushing facility. The C.A.'s physical parameters, such as specific gravity, bulk density, and gradation fineness modulus, are tested in compliance with IS 2386.

\section{3) GPRA Aggregate}

The shredded GPRA compound of less then $20 \mathrm{~mm}$ are obtained and is used in present study. The adding percentage of GPRA from $15 \%, 25 \%, 35 \%, 40 \%$.

\section{4) Fine Aggregate}

River sand, which was utilised as a fine aggregate, is a natural product that may be found on the local market. According to IS 2386, physical parameters such as specific gravity, bulk density, and gradation fineness modulus are examined. The Mix proportion of Concrete Mixes With aggregates in dry condition are shown in Table 1.

Table 1: Mix Proportioning of Concrete Mixes with Aggregate in Dry Condition

\begin{tabular}{|c|c|c|c|c|c|c|}
\hline \multirow{2}{*}{$\begin{array}{l}\text { Mix } \\
\text { designation }\end{array}$} & \multirow{2}{*}{$\begin{array}{l}\text { Cement } \\
(\mathrm{kg} / \\
\left.\mathrm{m}^{3}\right)\end{array}$} & \multirow[t]{2}{*}{ w/c } & \multirow{2}{*}{$\begin{array}{l}\text { Water } \\
\text { content } \\
\left(\mathrm{kg} / \mathrm{m}^{3}\right)\end{array}$} & \multirow{2}{*}{$\begin{array}{l}\text { Fine } \\
\text { Aggregate } \\
\left(\mathbf{k g} / \mathbf{m}^{3}\right)\end{array}$} & \multicolumn{2}{|c|}{$\begin{array}{l}\text { Coarse Aggregate } \\
\left(\mathrm{kg} / \mathrm{m}^{3}\right)\end{array}$} \\
\hline & & & & & GPRA & $\begin{array}{l}20 \mathrm{~mm}+ \\
10 \mathrm{~mm}\end{array}$ \\
\hline $\mathrm{CM}$ & 359 & 0.44 & 158 & 651 & 0 & $\begin{array}{l}751+500 \\
=1251\end{array}$ \\
\hline G10 & 359 & 0.44 & 158 & 651 & 125 & 1126 \\
\hline G20 & 359 & 0.44 & 158 & 651 & 250 & 1001 \\
\hline G30 & 359 & 0.44 & 158 & 651 & 375 & 876 \\
\hline G40 & 359 & 0.44 & 158 & 651 & 500 & 751 \\
\hline
\end{tabular}

\section{B. Methodology}

\section{1) Test On Fresh Concrete}

Slump testing with a metallic slump mould was used to determine the workability of all concrete mixtures. A depression was measured and characterised as the difference in grade between the height of the mud and the highest level of the subsided concrete. The slump tests were carried out as per IS 1199-1959. The details of same are mentioned in below Table 2 .

Table 2: Workability of GPRA Aggregate Concrete Mixtures and Control Concrete

\begin{tabular}{|c|l|l|l|l|}
\hline S. & \multirow{2}{*}{ Mix } & \multicolumn{3}{|l|}{ Workability } \\
\cline { 3 - 5 } & & $\begin{array}{l}\text { Slump } \\
(\mathbf{m m})\end{array}$ & $\begin{array}{l}\text { Compaction } \\
\text { factor }\end{array}$ & $\begin{array}{l}\text { Vee-Bee Time } \\
\text { (sec) }\end{array}$ \\
\hline 1 & CM & 105 & 0.88 & 16 \\
\hline 2 & G10 & 107 & 0.9 & 14 \\
\hline 3 & G20 & 110 & 0.91 & 13 \\
\hline 4 & G30 & 113 & 0.93 & 12 \\
\hline 5 & G40 & 117 & 0.95 & 11 \\
\hline
\end{tabular}

\section{1) Tests On Hardened Concrete}

Cubes of $150 \mathrm{~mm} \times 150 \mathrm{~mm} \times 150 \mathrm{~mm}, 150 \mathrm{~mm} \times 300 \mathrm{~mm}$ cylinders, and $150 \mathrm{~mm} \times 150 \mathrm{~mm} \times 600 \mathrm{~mm}$ as shown in fig 1 and 2. Beams were cut from each concrete mixture to determine compressive strength, splitting tensile strength, and flexural strength. The concrete specimens were cured under normal conditions for 3 days, 7 days, and 28 days before being evaluated for strength according to IS 5161959.

\section{2) Casting Of Specimen}

Fill the cube and cylinder moulds immediately after the sample has been remixed, then compact the concrete either by hand or by vibration. The strength of the cube and cylinder will be reduced if air is trapped in the concrete. The aggregates and cement paste in the mix may segregate if the concrete is over compacted. The cube's size $(150 \mathrm{~mm}$ $\mathrm{x} 150 \mathrm{~mm} \times 150 \mathrm{~mm}$ ) as shown in figure 3 .

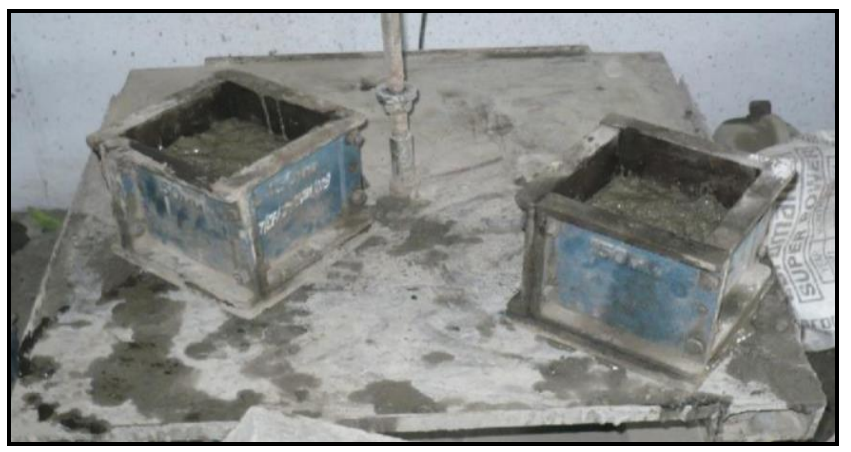

Figure 1: casting of cubes

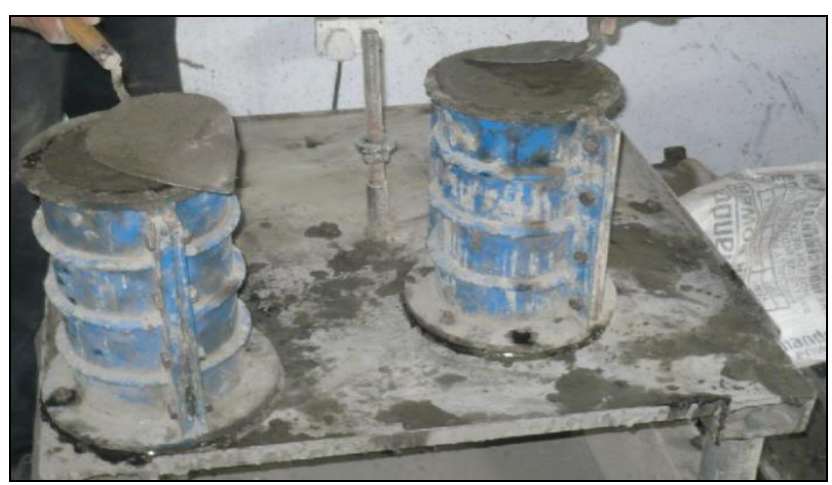

Figure 2: casting of cylinders

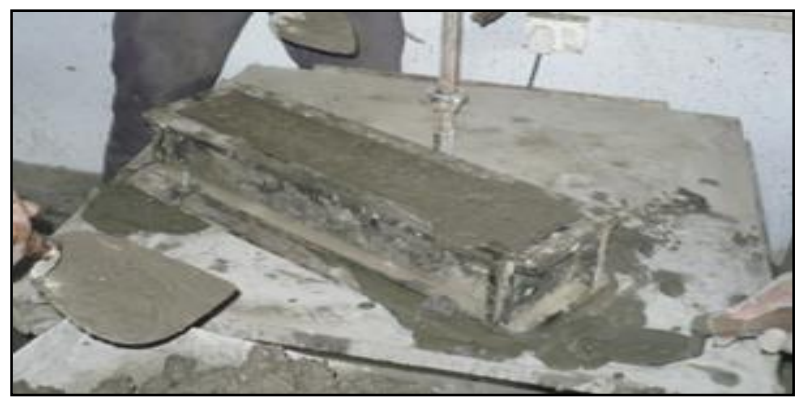

Figure 3: casting of beams 


\section{RESULTS AND DISCUSSION}

Table 3: compressive strength test at 3,7,28 days $10 \%, 20 \%, 30 \%, 40 \%$

\begin{tabular}{|c|c|c|c|c|c|}
\hline Sample & $\begin{array}{c}\% \text { of } \\
\text { GPRA }\end{array}$ & 3 days & 7 days & $\begin{array}{c}28 \\
\text { days }\end{array}$ & $\begin{array}{c}\text { Avg } \\
\text { (Mpa) }\end{array}$ \\
\hline 1 & 10 & 22.3 & 28.6 & 38.5 & \multirow{3}{*}{40.6} \\
\hline 2 & 10 & 20.6 & 30 & 42.5 & \\
\hline 3 & 10 & 19.5 & 26.4 & 4.08 & \\
\hline 1 & 20 & 17.6 & 31.1 & 38.6 & \multirow{3}{*}{39.3} \\
\hline 2 & 20 & 22.3 & 27.3 & 40.2 & \\
\hline 3 & 20 & 18.2 & 29.1 & 39.1 & \\
\hline 1 & 30 & 19.3 & 30.5 & 41.2 & \multirow{3}{*}{42.1} \\
\hline 2 & 30 & 20 & 33 & 44.0 & \\
\hline 3 & 30 & 21.2 & 29 & 41.1 & \\
\hline 1 & 40 & 17.2 & 27.5 & 36.2 & \multirow{3}{*}{35.2} \\
\hline 2 & 40 & 19.5 & 26.0 & 33.5 & \\
\hline 3 & 40 & 19.2 & 26.5 & 35.9 & \\
\hline
\end{tabular}

Table 4: Split Tensile Strength Test results

\begin{tabular}{|c|c|c|c|}
\hline Sample & \% of GPRA & 28 days (Mpa) & $\begin{array}{c}\text { Avg } \\
\text { (Mpa) }\end{array}$ \\
\hline 1 & 10 & 3.3 & \multirow{3}{*}{3.1} \\
\hline 2 & 10 & 2.9 & \\
\hline 3 & 10 & 3 & \\
\hline 1 & 20 & 2.1 & \multirow{3}{*}{2.06} \\
\hline 2 & 20 & 1.8 & \\
\hline 3 & 20 & 2.3 & \\
\hline 1 & 30 & 2.7 & \multirow{3}{*}{2.3} \\
\hline 2 & 30 & 2.2 & \\
\hline 3 & 30 & 2.3 & \\
\hline 1 & 40 & 1.5 & \multirow{3}{*}{1.83} \\
\hline 2 & 40 & 2.4 & \\
\hline 3 & 40 & 1.6 & \\
\hline
\end{tabular}




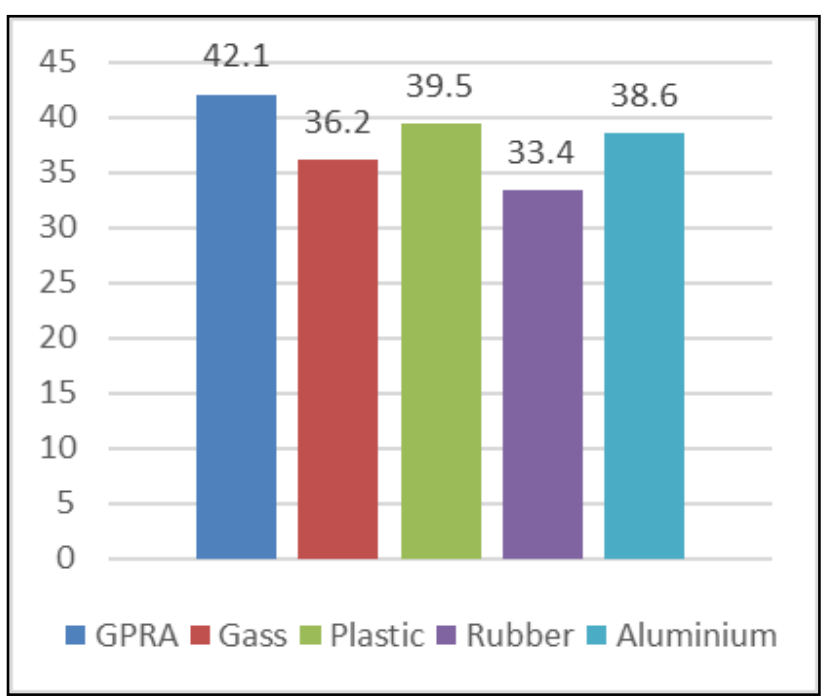

Figure 1: Compressive strength comparison of GPRA with Individual materials at $30 \%$ replacement

\section{A. Interpretation of Result}

- After 28 days we obtained the C.S. value of GPRA around $42 \mathrm{MPa}$ which is more than the design strength.

- From the above fig 5, we can clearly point out that the C.S. of GPRA is quite more than the individual replacement of the components.

- The maximum compression strength is obtained at $30 \%$ when replaced with C.A.

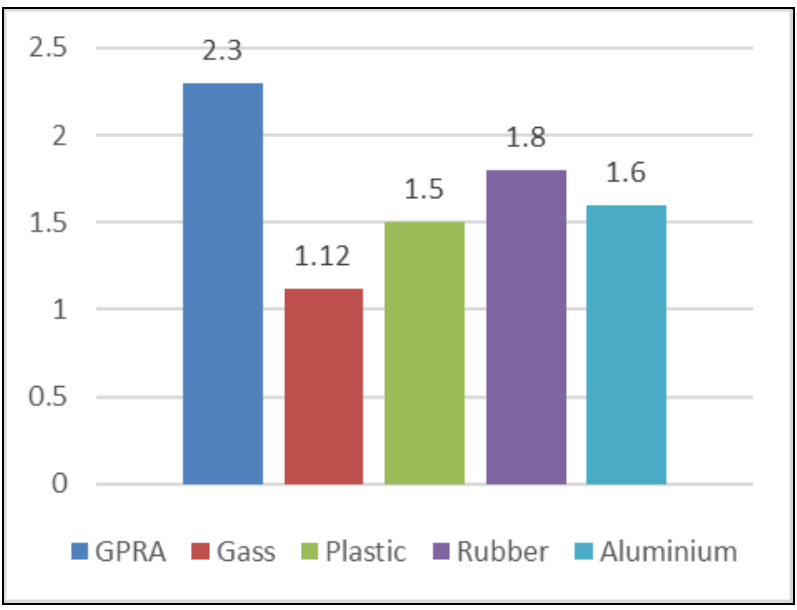

Figure 2: Split tensile strength comparison of GPRA with Individual materials at $30 \%$ replacement

\section{B. Interpretation of Result}

- After 28 days we obtained the S.T.S. value of GPRA around $2.3 \mathrm{MPa}$ which is more than the other values of individual components.

- From the above fig 6 , we can clearly point out that the S.T.S. of GPRA is quite more than the individual replacement of the components.

- The maximum S.T.S. is obtained at $30 \%$ when replaced with C.A.

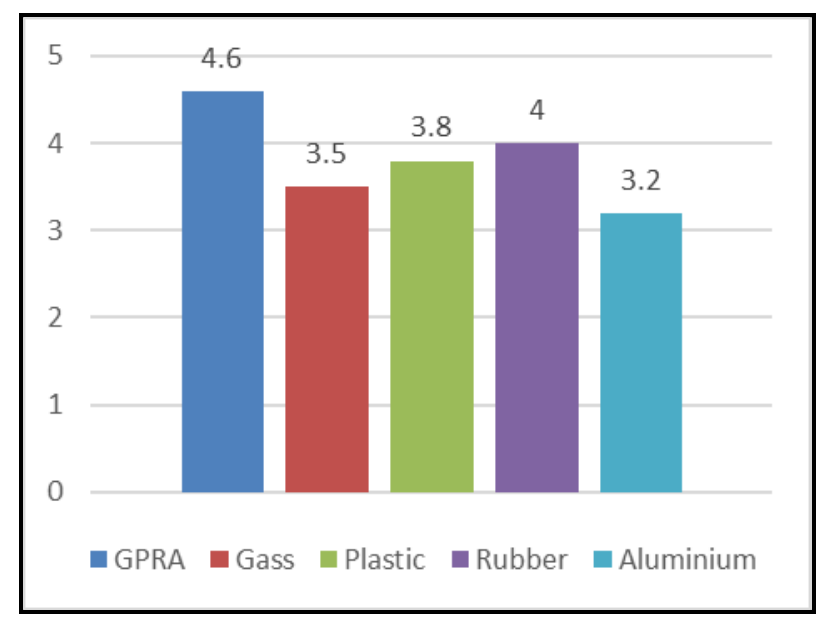

Figure 3: Flexural strength comparison of GPRA with Individual materials at $30 \%$ replacement

\section{Interpretation of Result}

- After 28 days we obtained the F.S. value of GPRA around 4.6 $\mathrm{MPa}$ which is more than the other values of individual components.

- From the above fig 7, we can clearly point out that the F.S. of GPRA is quite more than the individual replacement of the components.

- The maximum F.S. is obtained at $30 \%$ when replaced with C.A.

\section{CONCLUSIONS}

The investigation's major goal was to use waste materials collected from demolished structures, scrap, and wastes retrieved from junkyard locations. The use of these aggregates as a partial replacement for C.A. in concrete has a favourable impact on the environment while also lowering costs because these aggregates are readily available. They are less expensive than natural aggregates. Because GPRA material is simpler to come by and less expensive than natural aggregate, it is partially substituted with C.A.. Based on the compression strength test, S.T.S. test, and flexural test results, it is determined that GPRA aggregate can be used in place of C.A. with a specified proportion of replacement.

The following are the conclusions obtained after performing the above experiments.

- The maximum compression strength is obtained when $30 \%$ of C.A. was replaced with GPRA aggregate.

- The maximum S.T.S. is obtained when $30 \%$ of C.A. was replaced with GPRA aggregate.

- The C.S., S.T.S. and F.S. for $20 \%$ and $40 \%$ replacement of GPRA is not increased. There is little variation in the strength when compared with normal concrete. The optimum result is obtained for $30 \%$ replacement of GPRA with C.A.

- The C.S., S.T.S. and F.S. for $10 \%$ replacement of GPRA shows a increase but not more than $30 \%$ in most of the cases of test results. Also, if $10 \%$ replacement is to be adopted then the cost saving factor will be negligible. 
- The test results for individual materials at $30 \%$ replacement shows a low value of C.S., S.T.S. and F.S. as compared GPRA, thus the mixture of individuals materials combine in such a way to give more resilient and reliable concrete.

- By addition of GPRA aggregates into C.A., proper utilization of scrap waste can be achieved.

\section{A. Scope For Future Study}

From these experimental study results, the following recommendations can be made for future study.

- Testing the performance of GPRA on various grades of concrete

- Using sand and GPRA as fine aggregate in place of natural sand with different ratios and various grades of concrete

- Study on the performance of slab elements

- Higher level durability study can be carried out under UPV, Freeze-thaw weather, alkaline, low pH solution, permeability test, etc.

- Post cracking, Nonlinear \& SEM analysis, Mineralogical analysis by X-Ray Diffraction and Chemical analysis by XRay Fluorescence for FA. Compatibility with chemical admixtures.

\section{ABBREVIATIONS}

GPRA - Glass, Plastic, Rubber, Aluminum,

C.S. - Compressive Strength

S.T.S. - Split Tensile Strength

F.S. - Flexural Strength

C.A. - Coarse Aggregate

\section{CONFLICTS OF INTEREST}

The authors declare that they have no conflicts of interest.

\section{ACKNOWLEDGMENTS}

I would express my deepest gratitude to my guide Dr. Sandeep Kumar Chandel, Assistant Professor, Department of Civil Engineering, RIMT University Mandi Gobindgarh, who in every aspect helped and contributed in making this project. Our thanks to IJIREM CHI for allowing us to modify templates they had developed. Finally I would express deep love and warm regards to my family, without them this work wouldn't have been possible. I am highly indebted for their patience with me.

\section{REFERENCES}

[1] Dr. K. C. Reddy and Dinesh Kumar. 2017. Effect of Fly Ash and Aluminum powder on strength properties of concrete. International Journal of Research Publications in Engineering and Technology. Vol. 3, No. 7, 57-61.

[2] B. Harini and Ramana. 2015. Use of Recycled Plastic Waste as Partial Replacement for Fine Aggregate in Concrete. International Journal of Innovative Research in Science, Engineering and Technology, Vol. 4, No. 9, 8596-8603.

[3] Sara S., G. Carlo Marano., M. Borsa And M. Molfetta. 2010. Coventry University and The University of Wisconsin Milwaukee Centre for By-products Utilization, Second International Conference On Sustainable Construction Materials and Technologies. Ancona, Italy. June28-June30, 2010.

[4] R. Sakale., S. Jain., and Seema S. 2016. Experimental Investigation on Strength of Glass Powder Replacement by Cement in Concrete with Different Dosages. IJSTE. Vol. 2, No. 8, 76-86.

[5] T. Subramani., and V.K. Pugal. Experimental Study On Plastic Waste As A Coarse Aggregate For Structural Concrete. International Journal of Application or Innovation in Engineering \& Management (IJAIEM), Vol. 4 No. 5, (2015), 144-152. 